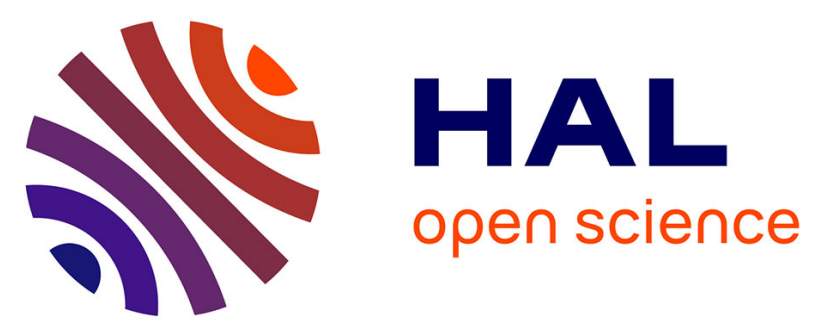

\title{
Insights into the structure of plant-insect communities: Specialism and generalism in a regional set of non-pollinating fig wasp communities
}

F. H. A. Farache, A. Cruaud, J.-Y. Rasplus, M. T. Cerezini, L. Rattis, Finn Kjellberg, R.A.S. Pereira

\section{To cite this version:}

F. H. A. Farache, A. Cruaud, J.-Y. Rasplus, M. T. Cerezini, L. Rattis, et al.. Insights into the structure of plant-insect communities: Specialism and generalism in a regional set of non-pollinating fig wasp communities. Acta Oecologica, 2018, 90, pp.49-59. 10.1016/j.actao.2018.02.006 . hal-02332952

\section{HAL Id: hal-02332952 https://hal.science/hal-02332952}

Submitted on 25 Oct 2019

HAL is a multi-disciplinary open access archive for the deposit and dissemination of scientific research documents, whether they are published or not. The documents may come from teaching and research institutions in France or abroad, or from public or private research centers.
L'archive ouverte pluridisciplinaire HAL, est destinée au dépôt et à la diffusion de documents scientifiques de niveau recherche, publiés ou non, émanant des établissements d'enseignement et de recherche français ou étrangers, des laboratoires publics ou privés. 
Insights into the structure of plant-insect communities: Specialism and generalism in a regional set of non-pollinating fig wasp communities

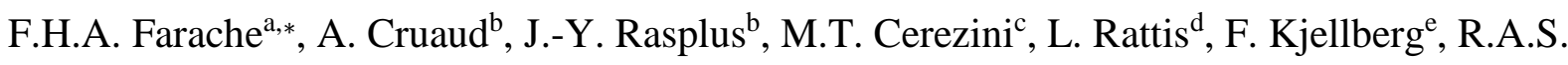
Pereira $^{\mathrm{a}}$

${ }^{a}$ Departamento de Biologia/FFCLRP-USP, Av. Bandeirantes, 3900, 14040-901 Ribeirão Preto, SP, Brazil b INRA - CBGP (CIRAD, INRA, IRD, Montpellier SupAgro, Univ. Montpellier), Montpellier, France ${ }^{c}$ PPG em Ciências Ambientais, Centro de Ciências Biológicas e da Saúde, UFSCar, Rodovia Washington Luís, km 235 - SP-310, 13565905 São Carlos, SP, Brazil d Woods Hole Research Center, 149 Woods Hole Road, Falmouth, MA, 02540, USA

e CEFE-UMR 5175, CNRS, Université de Montpellier, Université Paul-Valéry Montpellier 3, EPHE, IRD, 1919 Route de Mende, 34293 Montpellier Cedex 5, France 
Keywords: Agaonidae, Community ecology, Food web, Interaction network, Modularity, Moraceae

\begin{abstract}
Insects show a multitude of symbiotic interactions that may vary in degree of specialization and structure. Gallinducing insects and their parasitoids are thought to be relatively specialized organisms, but despite their ecological importance, the organization and structure of the interactions they establish with their hosts has seldom been investigated in tropical communities. Non-pollinating fig wasps (NPFW) are particularly interesting organisms for the study of ecological networks because most species strictly develop their offspring within fig inflorescences, and show a multitude of life history strategies. They can be gall-makers, cleptoparasites or parasitoids of pollinating or of other non-pollinating fig wasps. Here we analysed a set of non-pollinating fig wasp communities associated with six species of Ficus section Americanae over a wide area. This allowed us to investigate patterns of specialization in a diverse community composed of monophagous and polyphagous species. We observed that most NPFW species were cleptoparasites and parasitoids, colonizing figs several days after oviposition by pollinators. Most species that occurred in more than one host were much more abundant in a single preferential host, suggesting specialization. The food web established between wasps and figs shows structural properties that are typical of specific antagonistic relationships, especially of endophagous insect networks. Two species that occurred in all available hosts were highly abundant in the network, suggesting that in some cases generalized species can be more competitive than strict specialists. The Neotropical and, to a lesser extent, Afrotropical NPFW communities seem to be more generalized than other NPFW communities. However, evidence of host sharing in the Old World is quite limited, since most studies have focused on particular taxonomic groups (genera) of wasps instead of sampling the whole NPFW community. Moreover, the lack of quantitative information in previous studies prevents us from detecting patterns of host preferences in polyphagous species.
\end{abstract}

\title{
1. Introduction
}

Interaction networks arise in a multitude of contexts such as social sciences (Burt, 1976; Friedkin and Johnsen, 1997), communication (Dorogovtsev and Mendes, 2003), molecular biology (Ma'ayan, 2011), and ecology (Bascompte and Jordano, 2006; Jordano, 1987; Memmott, 1999). Although network analysis is applied to different disciplines, organization levels and organisms, general patterns and unifying concepts can be used to describe their structure, such as centrality, connection intensity, interaction strength and modularity (Barrat et al., 2004; Brandes et al., 2003; Dunne et al., 2002; Olesen et al., 2007). In an ecological perspective, the characteristics of interaction networks have been investigated to detect emergent patterns in areas such as food webs, pollination ecology, seed dispersal and parasitic interactions. They allow addressing important questions such as vulnerability to extinction, ecological specialization, and pollination efficiency (Bascompte et al., 2006; Blüthgen et al., 2007; Memmott, 1999; Memmott et al., 2004; Taudiere et al., 2015). In the context of 
plantanimal interactions, ecological network analysis contributes to the recognition of generalism and specialization patterns among species.

Such patterns may allow detecting the presence of underlying processes driving evolutionary diversification in symbiotic communities, concerning both antagonistic and mutualistic relationships (Forister and Feldman, 2011).

Plant-insect interaction networks vary in structure, yet some emerging patterns have been uncovered according to the type of interaction established. Mutualistic networks such as pollination and seed dispersal interactions tend to show nested structures that are cohesively organized around a central core of generalized interactions. This pattern has been hypothesized to arise from diffuse coevolution between plants and animals, and generates heterogeneous distributions of the number of interactions (Bascompte et al., 2003). On the other hand, specialized networks, organized around herbivorous insects and plants, or insects and their parasitoids, tend to show cohesive groups of animals associated with subsets of hosts, often called compartments or modules (Dormann and Strauss, 2014) which are generated by ecological or evolutionary trophic specialization (Olesen et al., 2007; Prado and Lewinsohn, 2004). Therefore, network structure may indicate the presence of underlying evolutionary mechanisms that generate the level of specialization/generalization observed within plant-insect communities.

The communities of micro-hymenopterans associated with fig trees (Ficus, Moraceae) may provide a powerful model to investigate processes driving the evolution of community structure. Indeed, these wasps include diversified sets of gall inducing wasps, cleptoparasites and parasitoids (Elias et al., 2012; Segar et al., 2013a). Further, most of these wasps breed exclusively within figs (the closed inflorescence of Ficus), and the adults of the different species emerge synchronously from their host fig. Therefore collecting whole communities is relatively easy. Furthermore, sampling the wasps emerging from all local Ficus species allows collection of the whole meta-community of fig wasps, and therefore they offer robust data for analysing the interconnections between the different communities using a network approach. Since each wasp utilizes a single fig flower ovary as oviposition site, and the cleptoparasites and parasitoids utilize a single larva to develop, it is straightforward to obtain a comparable quantitative measure of the degree of infestation for each species in each host. Therefore, we have a robust measure of the reproductive output of each wasp species in each host, and it is possible to obtain highly informative networks.

The relationship between fig trees and Agaonidae is a classic example of obligatory pollination mutualism. The fig is an urn-shaped inflorescence, which is lined inside by hundred(s) to thousands of uniovulate flowers depending on the Ficus species. Female pollinating wasps enter the fig by crawling through an aperture closed by bracts (the ostiole), oviposit in the ovaries of some pistillate flowers and pollinate others. The wasp larva develops instead of a would-be seed. Male offspring emerge into the fig cavity and mate with the females that are still enclosed in their galls. Then, female wasps emerge from their galls, leave the fig 
and fly to another fig to oviposit and pollinate (Galil and Eisikowitch, 1969). Global phylogenetic analyses of Ficus and Agaonidae show that these groups have broadly radiated in parallel (Cook and Segar, 2010; Cruaud et al., 2012; Machado et al., 2005). Generally, each Ficus species is pollinated by one or a few speciesspecific agaonid wasps (for exceptions see e.g. Cornille et al., 2012).

Besides pollinators, fig inflorescences host species-rich chalcid wasp communities. Indeed, several unrelated lineages of chalcid wasps develop exclusively or mainly on figs (Bouček, 1993; Rasplus et al., 1998). They interfere with the reproductive success of both Ficus and pollinating wasps in different ways, as they differ widely in feeding habits (Elias et al., 2007; Peng et al., 2005). Some non-pollinating fig wasps (NPFW) induce galls and their offspring develop in pistillate flowers as pollinators do (Elias et al., 2012; Jansen-Gonzalez et al., 2014); in some cases, they may even induce galls in other fig tissues or organs (Beardsley and Rasplus, 2001; Bronstein, 1999; Ghara et al., 2014; Müller, 1886). Some phytophagous NPFWs (known as inquilines or cleptoparasites) feed on galls induced by other wasps and eliminate their larvae in the process (Joseph, 1958), while other groups are true parasitoids that feed directly on the larvae of phytophagous fig wasps (Tzeng et al., 2008) Finally, some wasps are facultative (Pereira et al., 2007) or obligatory seed eaters (Wang et al., 2014). Despite increasing interest in their biology and evolution (Cruaud et al., 2011a, 2011b; Elias et al., 2008), the communities of NPFW are poorly known (but see Compton and Hawkins, 1992; Compton and van Noort, 1992;

Kerdelhué et al., 2000; Segar et al., 2013b). Information on host specificity of NPFW is scarce and limited by sampling effort and lack of taxonomic resolution (Cook and Segar, 2010; Darwell and Cook, 2017). Thus, the level of host specificity in NPFW is subject to debate. In some lineages, host specificity is supported by evidence for parallel cladogenesis between Ficus and NPFWs (Jousselin et al., 2006). However, in some other studies, co-phylogenies suggest considerable host switching during their evolutionary history (Jiang et al., 2006). Datasets on Neotropical and African fig wasps show some NPFW species colonizing several hosts (Marussich and Machado, 2007; McLeish et al., 2012). These results suggest that host specificity and strict-sense co-evolution may not satisfactorily explain the diversification of NPFW and their host species.

In this context, we analysed a set of NPFW communities associated with Ficus section Americanae in three areas of semi-deciduous forests in São Paulo state, Brazil. Large-scale sampling allowed us to thoroughly investigate patterns of specialization in a complex community composed of monophagous and polyphagous species with an array of life histories and a wide range of abundances in each Ficus host. As fig wasps have a delimited set of potential oviposition sites (one egg in each pistillate fig flower) and we measured the ovule occupancy rate of individuals belonging to each wasp species in the community in each host, our data allowed us to assess the ecological specialization of NPFW species with a quantitative network approach. Specifically, we aimed at answering the following questions: (1) how often 
do the offspring of a NPFW species develop in more than one host; (2) are NPFW communities specialized; (3) do NPFW communities present a structured pattern; (4) even if wasp species use several hosts, is the species composition of the community associated with each of these hosts different. Furthermore, extra-Amazonian Brazil in general - and São Paulo state in particular - has suffered from huge deforestation. Such a situation may have impacted NPFW communities. A simple prediction is that the communities associated with the least common Ficus species may be strongly affected, showing species-poor communities and a lack or imbalance in some trophic levels, while the community associated with the most abundant Ficus species may be more typical.

\section{Material and methods}

\subsection{Studied species}

We analysed the NPFW communities associated with six Ficus species belonging to the section Americanae in three locations in São Paulo state, Brazil. Ficus sect. Americanae is the most diverse Ficus section in the Neotropical region, with more than 120 described species (Berg and Villavicencio, 2004). The Ficus species present locally included seven species of section Americanae and two species of section Pharmacosycea. We verified that the NPFW genera associated with Ficus section Americanae and with section Pharmacosycea were distinct. The communities associated with the later group were not investigated in this study. Figs belonging to section Americanae are monoecious, and the studied species vary in average fig diameter from $\sim 1$ to $\sim 2.5 \mathrm{~cm}$ when mature

(Table 1).

Ficus section Americanae is a clade that only diversified recently between the Oligocene and Miocene ( 20-25 Ma, Cruaud et al., 2012; Machado et al., 2018). The group is monophyletic, but phylogenetic relationships within section Americanae are not well established (Cruaud et al., 2012; Machado et al., 2018). Species may grow as hemiepiphytes or as free standing trees (Berg and Villavicencio, 2004).

Table 1

Ficus section Americanae species sampled in this study, showing their characteristics (fig diameter and number of flowers per fig). Number of figs quantified and crops sampled in this study are also shown. Total of qualitative and quantitative samples is also divided by sample area (Gália/Ribeirão Preto/Teodoro Sampaio).

\begin{tabular}{llllll}
\hline Host & $\begin{array}{l}\text { Fig diameter }(\mathrm{X} \pm \\
\mathrm{SD} \mathrm{cm})\end{array}$ & $\begin{array}{l}\text { No female flowers per } \\
\text { fig }(\mathrm{M} \pm \mathrm{SD})\end{array}$ & $\begin{array}{l}\text { No of } \\
\text { figs }\end{array}$ & $\begin{array}{l}\text { No of samples } \\
\text { qualitative }\end{array}$ & $\begin{array}{l}\text { No of samples } \\
\text { quantitative }\end{array}$ \\
\hline F. citrifolia & $1.4 \pm 0.2$ & $550.4 \pm 183.8$ & 1024 & $58(20 / 17 / 21)$ & $51(17 / 17 / 17)$ \\
F. crocata & $2.3 \pm 0.3$ & $1460.1 \pm 444.7$ & 157 & $12(1 / 0 / 11)$ & $8(0 / 0 / 8)$ \\
F. eximia & $1.4 \pm 0.2$ & $642.4 \pm 224.2$ & 548 & $38(13 / 13 / 12)$ & $30(10 / 10 / 10)$ \\
F. & $0.9 \pm 0.1$ & $329.3 \pm 115.8$ & 100 & $6(1 / 0 / 5)$ & $5(1 / 0 / 4)$ \\
luschnathiana & & & & &
\end{tabular}




\begin{tabular}{llllll} 
F. obtusifolia & $1.9 \pm 0.3$ & $874.5 \pm 214.0$ & 165 & $15(11 / 3 / 1)$ & $8(4 / 3 / 1)$ \\
F. trigona & $1.0 \pm 0.2$ & $270.2 \pm 81.6$ & 59 & $4(2 / 2 / 0)$ & $3(2 / 1 / 0)$ \\
\hline
\end{tabular}

Despite some species in section Americanae presenting cauliflory, all species analysed in this study bear figs in the leaf axils or just below the leaves. Fig production within individual species varies in relation to growth form and size. For instance, Ficus citrifolia usually grows as a small hemiepiphyte and produces relatively small crops of a few thousand figs, whereas F. luschnathiana and F. trigona grow as hemiepiphytes or small trees and produce medium-sized crops. Ficus obtusifolia, F. crocata and F. eximia may be terrestrial or hemiepiphytic, usually have large tree crowns and produce larger crops.

Non-pollinating fig wasps occurring in the sampled fig trees include two genera belonging to the Agaonidae (Sycophaginae; Anidarnes Bouček and Idarnes Walker), one Eurytomidae genus (Sycophila Walker), three Pteromalidae genera (Aepocerus Mayr, Ficicola Heydon, and Heterandrium Mayr), and two genera belonging to the Torymidae (Nannocerus Mayr and Physothorax Mayr) (see: Bouček, 1993; Rasplus et al., 1998, for further systematic information).

\subsection{Oviposition time and feeding regime}

We considered these NPFW as belonging to three different ecological groups according to their timing of oviposition. Anidarnes, Idarnes group incertus and Ficicola are large gall inducers that colonize figs well before pollination and lay eggs in developing pistillate flowers or sometimes in the fig wall (Bronstein, 1999; Conchou et al., 2014; Müller, 1886). We will refer to these species as "prefloral colonizers".

Idarnes species belonging to the flavicollis species group are also gall inducers, and oviposit in pistillate flowers at the same time as pollinators. We will refer to these species as "receptive phase colonizers" since they are seen on figs during the anthesis of the pistillate flowers (Elias et al., 2012). Their galls are almost the same size as pollinator galls and they may compete with them for oviposition sites.

Idarnes species belonging to the carme species group colonize figs after pollination - some species immediately after - and use galls induced by other wasps as oviposition sites, killing the host larva in the process (Elias et al., 2008; Pereira et al., 2007). Thus, they can be considered as cleptoparasites. Species belonging to the remaining wasp genera (Heterandrium, Nannocerus, Physothorax and Sycophila) also oviposit after pollination and are probably parasitoids or cleptoparasites of other fig wasps (Elias et al., 2008). We refer to these species as "interfloral colonizers".

Observations on the biology of Aepocerus in French Guiana suggested that at least one species arrives at the same time as the pollinator, and may be a gall inducer (Conchou et al., 2014), however, we observed that a species associated with F. citrifolia in Ribeirão Preto 
(Brazil) arrived well after pollination, suggesting that feeding regime variation is present within this genus; thus, they can be either gallers or cleptoparasites/parasitoids.

\subsection{Data sampling and study locations}

From September 2007 to December 2010 we collected samples within fragments of semideciduous Atlantic Forest and surrounding areas. Sampling locations encompassed the cities of Ribeirão Preto $\left(21^{\circ} 10^{\prime} \mathrm{S}, 47^{\circ} 48^{\prime} \mathrm{W}\right)$, Gália $\left(22^{\circ} 24^{\prime} \mathrm{S}, 49^{\circ} 42^{\prime} \mathrm{W}\right)$, Teodoro Sampaio $\left(22^{\circ} 26^{\prime} \mathrm{S}\right.$, $52^{\circ} 18^{\prime} \mathrm{W}$ ), and adjacencies. The three sites were located ca. 200-500 Km apart. A systematic survey of the abundance of the different fig species in the same locations provides density data within remaining forest patches for the different plant species (Coelho et al., 2014). We sampled all host species from section Americanae reported in Coelho et al. (2014) except F. lagoensis. Mature individuals of this host produced figs very sporadically and could not be sampled. Our sampling regime therefore covered the most common host species distributed throughout this biome, but excluded host species with a restricted distribution and species that are cultivated in urban areas but are probably introduced from other biomes.

For each reproductive episode (crop) of a tree, we collected about 20-50 figs just before ripening and transferred them to netting bags until the wasps emerged. Figs were opened after $24 \mathrm{~h}$ and further kept for 2-6 days; wasps were collected every 12-24 h. Wasps were killed by freezing and placed into $70 \%$ ethanol. Thereby we obtained qualitative information on species richness in each crop. For most crops, ca. 20 additional figs were kept individually in plastic flasks until the wasps emerged. We collected all emerged wasps from each fig, and unemerged wasps were removed from the galls. Thus, we could count numbers of wasps of each species in each fig. Because male wasps are often somewhat difficult to associate to females of the same species within a genus, we present numerical data for females only. We also quantified the number of female flowers, estimated by the summation of unused flowers, seeds, empty galls ('bladders'), and developed galls (i.e., the total number of wasps, since a single wasp emerge from each gall). The number of seeds, empty galls and unused flowers were estimated for the whole fig by counting these structures in one fourth of each fig in larger figs (i.e. F. citrifolia, F. crocata, F. eximia and F. obtusifolia). For smaller figs (i.e. F. luschnathiana and F. trigona) these structures were counted in the whole fig. The total number of flowers was used to standardize sampling effort as it yields a good measure of the fig size.

\subsection{Species delimitation and voucher materials}

Collected specimens were assigned to morphospecies based on their external morphology. Some specimens were card or point-mounted in order to facilitate identification and comparison. Our morphological identification method was validated by molecular investigation within Idarnes species, including 12 species and 49 samples (more details of our morphological analyses and molecular confirmation are given in supplementary data 1). Hence, at least in extra-Amazonian Brazil, it is possible to sort NPFW to species under a stereoscopic 
microscope, allowing us to achieve large sample sizes. Transposition of the morphological technique used here to other continents should be tested. More importantly, we confirmed that the numerically most important NPFWs in our study system used several hosts, so that the most striking results presented below are based on morphological assignations confirmed by molecular data.

\subsection{Multivariate qualitative analysis}

We performed multivariate analyses to compare samples (crops) from different host fig species and different locations in relation to their associated wasps. We built a binary community data matrix where lines represented the samples and columns represented wasp species occurring in each sample; then we calculated the Jaccard dissimilarity indices for the data matrix and performed UPGMA hierarchical clustering (Legendre and Legendre, 1998). The cluster topology was analysed to evaluate whether samples clustered according to host species or according to locality. In addition, clustering effects of host species and locality were evaluated using distance-based permutational multivariate analysis of variance (PERMANOVA; Anderson, 2001; McArdle and Anderson, 2001) on the Jaccard dissimilarity matrix, with 9999 resampling permutations. Since our sampling was unbalanced we also performed PERMANOVA analyses using just samples collected in F. citrifolia and F. eximia (see Table 1 for sampling effort). Analyses were performed using R 3.2.3 (R Core Team, 2017) packages vegan (Oksanen et al., 2017) and ggdendro (de Vries and Ripley, 2016).

\subsection{Food web analyses}

To measure linkage strength between wasp species and host plants we constructed a quantitative bipartite food web showing the abundance of NPFW species divided by the number of female fig flowers observed in each host. Plants and insects were ordered with a canonical correspondence analysis - CCA - to minimize interaction overlaps. We also plotted the twomode projection as unweighted binary graphs in order to visually evaluate the centrality of each species in the network (Brandes et al., 2003; Martín González et al., 2010).

We estimated the network connectance to describe the number of interactions observed in the food web in relation to the maximum number of possible interactions in the matrix. Connectance varies from 0 (no interactions) to one (all species interact with each other). We measured the degree of specialization in the entire network using standardized two-dimensional Shannon entropy index $\left(\mathrm{H}_{2}\right)$. It standardizes $\mathrm{H}_{2}^{\prime}$ between maximum and minimum $\mathrm{H}_{2}$ entropy, ranging from 0 (extreme generalization) to 1 (extreme specialization) (Dormann et al., 2009).

In order to evaluate the structure of the community, we analysed nestedness and modularity indices (Bascompte and Jordano, 2006). Nestedness describes a food-web pattern in which specialist species interact with specific subsets of species that interact with the more generalist ones (Bascompte et al., 2003). The weighted NODF index describes the level of nestedness 
within the community (Galeano et al., 2009) and varies between 0 (complete chaos) and 100 (completely nested).

Modules are aggregated groups of species that interact more with each other than with other species in the network. In order to test for modularity we used the QuanBiMo algorithm that identifies modules in weighted networks (Dormann and Strauss, 2014). The algorithm was allowed to run for $10^{9}$ generations.

We compared the indices estimated for the food web with null models generated with the Patefield algorithm (Patefield, 1981), in which marginal totals are maintained constant, using 1000 replications. For $\mathrm{H}_{2}^{\prime}$ comparisons, null models were generated with the algorithm proposed by Vázquez et al. (2007) in which marginal sums and connectance are kept constant, using 1000 replications.

Network-level analyses were carried out for the complete network and for two subsets of species that have similar ecological niches: one comprising the galler species (large gall inducers and receptive-phase colonizers), and the other one comprising cleptoparasites/parasitoids. As the life history of Aepocerus spp. is dubious, we included these species only in the analyses with the complete network.

We used three species-level indices that describe host specialization (Dormann, 2011) to evaluate specificity of each species in the community. (1) The resource range is a qualitative index that estimates specificity based on the subset of resources exploited with a non-zero performance. It varies from zero, when a species uses all available hosts, to one, when a species occurs in a single host (Poisot et al., 2012). (2) The paired difference index (PDI) contrasts a species' strongest link with those over all remaining resources, and it was considered a robust index to differentiate specialism and generalism (Poisot et al., 2012). The index varies between 0 and 1; absolute values below 0.5 suggests generalism, while values above 0.5 suggests specialism (Poisot et al., 2012). (3) The weighted betweenness describes the centrality of a species in the network by its position between other nodes based on the weighted representation of the network (Butts, 2014). It varies from zero, indicating that the species is peripheral in the network, to one, indicating that the species is central in the network.

All analyses were performed using $\mathrm{R}$ version 3.2.3 (R Core Team, 2017) and the packages "vegan" (Oksanen et al., 2017), "bipartite" (Dormann, 2011; Dormann et al., 2008, 2009) and "sna" (Butts, 2014). The raw datasets used for community analyses are available in supplementary data 2.

\section{Results}

\subsection{NPFW community structure and host utilization}

We sampled 133 crops from six Ficus species and obtained quantitative data for 105 samples. A total of 111,555 NPFW specimens were identified to morphospecies (Table 1 and supplementary data 2). Fortytwo NPFW morphospecies belonging to eight genera were 
recognized, and from those, 19 (45\%) occurred in more than one host (Fig. 1, Fig. 2). Idarnes was the most species-rich genus observed in the fig species we sampled (Fig. 1).

Prefloral colonizers usually occurred at low abundances, representing less than $2 \%$ of the total number of NPFW collected, but represented $21 \%$ of all sampled species ( 9 spp.). Receptive phase colonizers were less diversified ( $3 \mathrm{spp}$., $7 \%$ of the sampled species, Fig. 1), but usually occurred in higher abundances (supplementary data 3). They represented between $7 \%$ (F. trigona) and $82 \%$ (F. luschnathiana) of the female individuals of NPFW emerging from figs. Most species were interfloral colonizers (25 spp., $60 \%$ of the total number of NPFW, Fig. 1) and presented a wider range of abundances (supplementary data 3). Five species (12\%) belonged to Aepocerus, which may be receptive phase or interfloral colonizers.

Most NPFW species associated with each Ficus species occurred in more than one host. About 11-33\% of the species occurring in each host were strictly specific (Fig. 2). However, for 12 out of 19 species that occurred in multiple hosts, the relative abundance in their main host was $>75 \%$ (Fig. 3, supplementary data 2).

The network was clearly dominated by species of genus Idarnes, which represented $86 \%-$ 99\% of all female NPFW specimens in a particular host, except in Ficus trigona with only 59\% of Idarnes. Among Idarnes, two species were particularly abundant: the gall-maker I. flavicollis (If06) and the cleptoparasite Idarnes sp. 9 (Ic09). Both of these species occurred in all host species and were also the most abundant NPFW in several hosts (Figs. 2 and 3A, supplementary data 3).

\subsection{Similarity of the NPFW fauna among hosts and locations}

Although some NPFW species used several hosts, we observed that the samples analysed clustered by Ficus species (Fig. $4 ; \mathrm{R}^{2}=0.50$ or 0.43 depending on whether all host species were included or not, Table 2). The clustering pattern due to the sampling location and to the interaction between host species and location were significant but these effects were comparatively weaker and accounted for much less of the deviance $\left(\mathrm{R}^{2}=0.04\right.$ or 0.07 Table 2$)$ than the clustering by fig host. Interestingly there was no clear pattern of differentiation within host fig species among regions in the UPGMA grouping of samples. Some samples from F. luschnathiana and F. trigona did not cluster together due to the low proportion of strictly specific species (Figs. 2 and 4). 

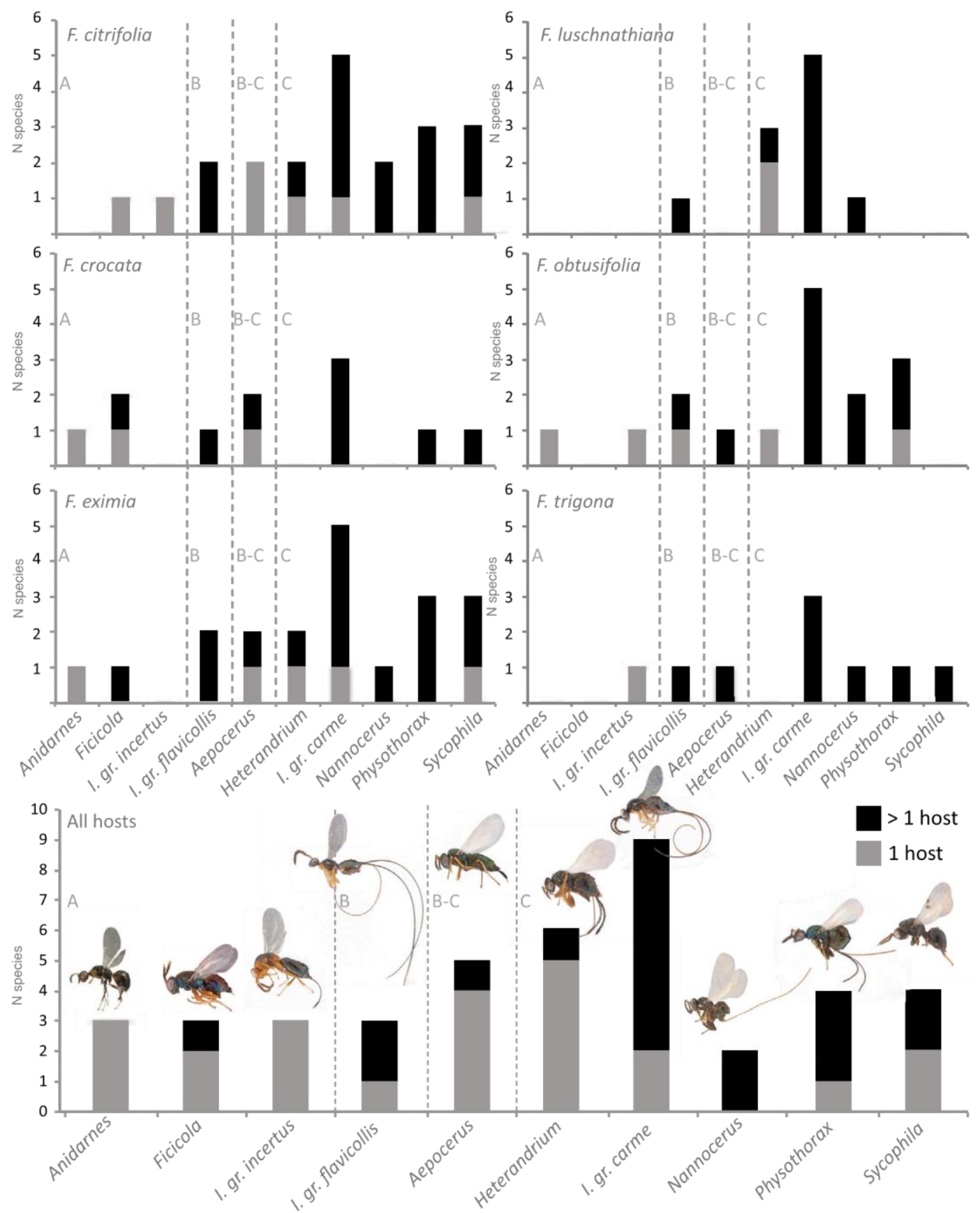
Fig. 1. Species richness for NPFW genera associated with sampled Ficus species. Bar colours indicate strictly specific (grey) and species that occurred in more than one host (black). Species are ordered by the fig developmental phase in which each wasp species arrive: $\mathrm{A}=$ Early gall inducers; $\mathrm{B}=$ receptive phase colonizers; $\mathrm{B}-\mathrm{C}$ receptive or interfloral phase colonizer; and $\mathrm{C}=$ interfloral phase colonizers.

\subsection{Specialization and food web structure}

Quantitative food web analyses showed that the interaction between NPFW and Ficus sect. Americanae presented low connectance and high specialization $\mathrm{H}_{2}^{\prime}$, compared with null models $\left(\mathrm{c}=0.33 ; \mathrm{H}_{2}{ }^{\prime}=0.65 ;\right.$ Table 3$)$. This pattern was also observed when investigating separately the gall-maker and cleptoparasite/parasitoid subsets (Table 3).

The weighted NODF was significantly lower than observed in null models $(\mathrm{wNODF}=22.7$, $\mathrm{P}<10^{-3}$; Table 3); hence the network was not nested. Indeed, the QuanBiMo algorithm indicated a modular structure in the network $(\mathrm{Q}=0.53 ; \mathrm{P}<0.01)$, and mostly each host represented an independent module, except F. crocata and F. obtusifolia (Fig. 3B) that belonged to the same module. Analyses on the gall-maker and cleptoparasite/parasitoid subsets also showed the same modular structure (Table 3).

The species-level indices show that despite some species presenting a broad host range (Fig. 5 ), they are mostly specific when quantitative data was analysed (PDI $>0.73$ for all species). In fact, $85 \%$ of the species were very specialized (PDI $>0.9$ ), and only three of them showed a comparatively high centrality in the network (weighted betweeness $>0.1$ ). Species arriving before fig receptivity were mostly highly specialized, while species arriving at receptive phase and onwards showed both slightly generalized species and extreme specialists (Fig. 5). The PDI was significantly higher than expected by the null models even for the most generalized species, except for Sycophila sp. 3 (Table 4), due to the low number of individuals sampled ( $\mathrm{N}=10$ individuals). 


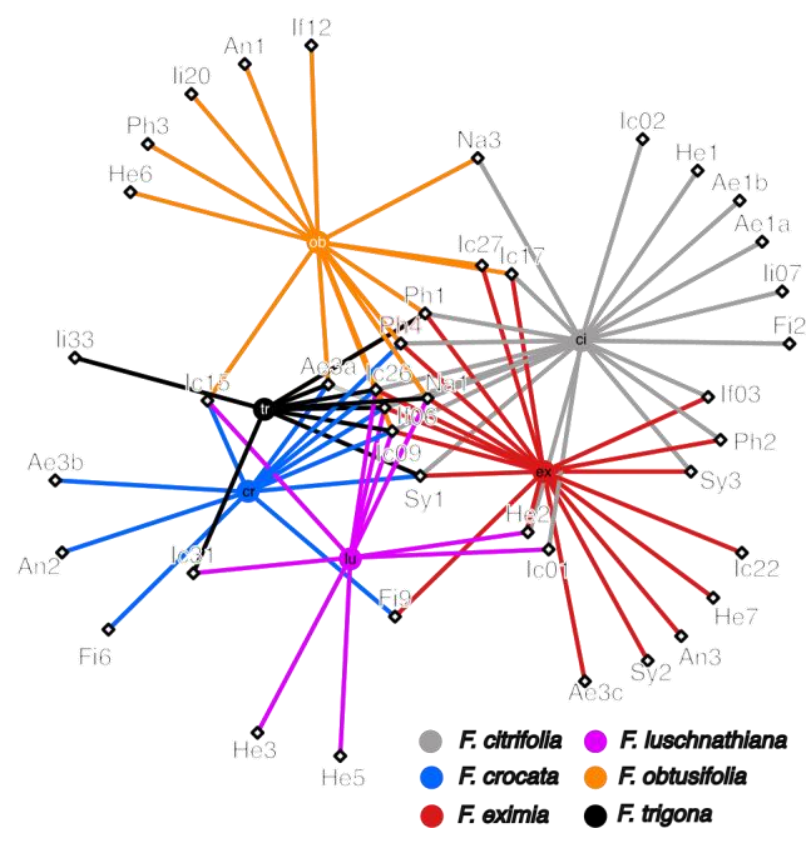

Fig. 2. Two-mode projection network of NPFW occurring in Ficus species sampled (unweighted). Abbreviations for hosts: $\mathrm{ci}=\mathrm{F}$. citrifolia; $\mathrm{cr}=\mathrm{F}$. crocata; ex $=\mathrm{F}$. eximia; $\mathrm{lu}=\mathrm{F}$. luschanthiana; $\mathrm{ob}=\mathrm{F}$. obtusifolia; $\mathrm{tr}=\mathrm{F}$. trigona. Abbreviations for wasp genera and species groups: $\mathrm{Ae}=$ Aepocerus; $\mathrm{An}=$ Anidarnes $; \mathrm{Fi}=$ Ficicola $; \mathrm{He}=$ Heterandrium; $\mathrm{Ic}=$ Idarnes group carme; If = Idarnes group flavicollis; $\mathrm{Ii}=$ Idarnes group incertus; $\mathrm{Na}=$ Nannocerus; $\mathrm{Ph}=$ Physothorax; Sy = Sycophila.

\section{Discussion}

In this study we described the community structure and patterns of specialism/generalism in NPFW associated with Ficus section Americanae. This is the first study providing a large quantitative dataset on all the NPFW emerging from a regional community of Ficus species. Several species were not strict specialists and emerged from at least two host species. Nevertheless, a majority of NPFW species were specialists and emerged from a single Ficus host. Some species, despite occurring in more than one host, showed higher abundance in a particular host species, which may indicate a strong host preference or a more efficient reproduction in this host. A few NPFW were produced in similar numbers by two hosts, and the two most abundant species, a receptive phase colonizer (Idarnes flavicollis - If06) and a cleptoparasite (Idarnes group carme sp. 09 - Ic09) occurred in all hosts.

We observed that the different host species showed variation in the composition of their associated NPFW community. The community of NPFW associated with F. citrifolia (the most abundant host species in all habitats - Coelho et al., 2014) followed the classical pattern as understood from other regions of the world, with an assemblage of mostly specialist species, including typical proportions of the different functional groups (Segar et al., 2013b). The NPFW 
community associated with F. luschnathiana was the only community dominated by a single species, the generalist gall-maker Idarnes flavicollis (If06), representing more than $80 \%$ of the emerging NPFW individuals. Idarnes flavicollis emerged in much larger numbers from several other fig species (supplementary material 2). We propose that F. luschnathiana is present at such low densities (Coelho et al., 2014) that it can only sustain a very limited and generalist complement of NPFW fauna, leaving much empty space (non-utilized flowers). Moreover, a lower abundance of pollinators and gall inducers may contribute to a reduced fauna of cleptoparasites and parasitoids.

Fig. 3. A) Bipartite network of NPFW and their hosts. Line widths represent the relative abundance of each species in each host (number of specimens/number of flowers analysed). Box heights in the higher level represent the phase in which each wasp species arrive: $\mathrm{A}=$ Early gall inducers; $\mathrm{B}=$ receptive phase colonizers; $\mathrm{B}-\mathrm{C}$ receptive or interfloral phase colonizer; and $\mathrm{C}=$ interfloral phase colonizers. B) Quantitative module analysis of the network generated by the QuanBiMo algorithm. Color intensity represents the relative abundance of each species (columns) in their fig hosts (rows). Rectangles indicate modules. Abbreviations for genera follow Fig. 2.

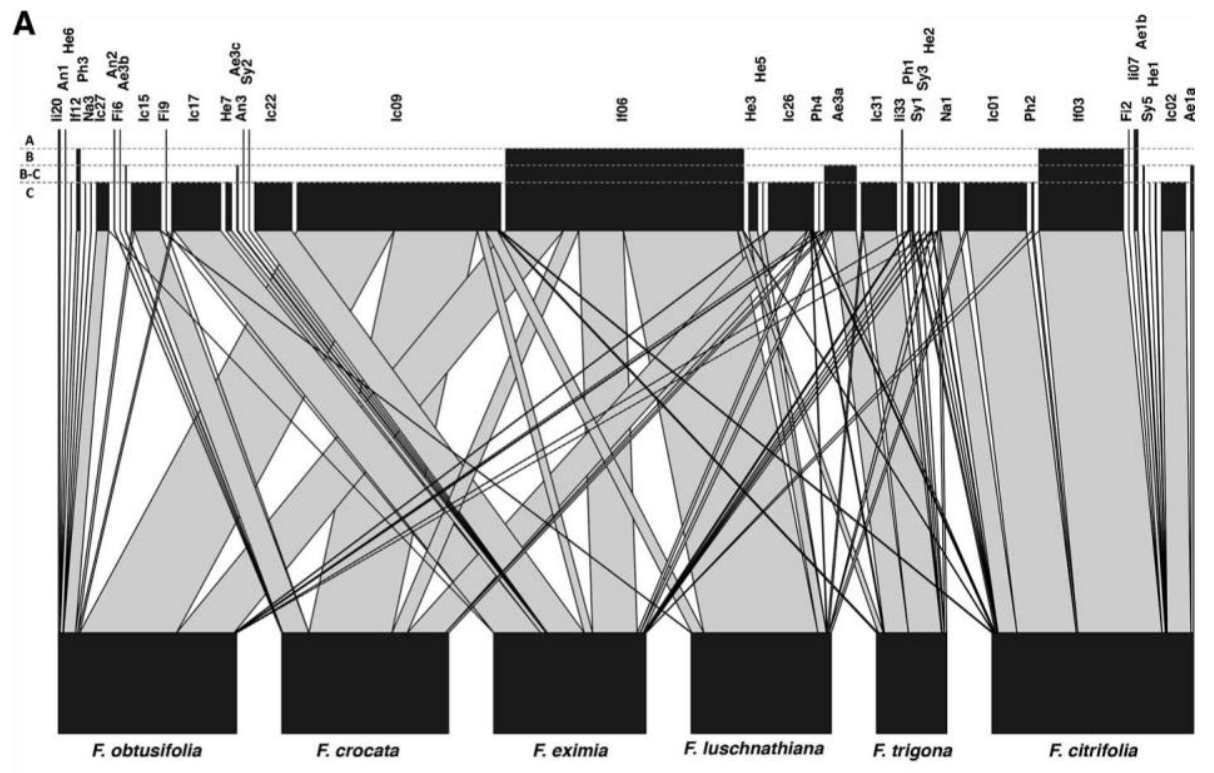

B

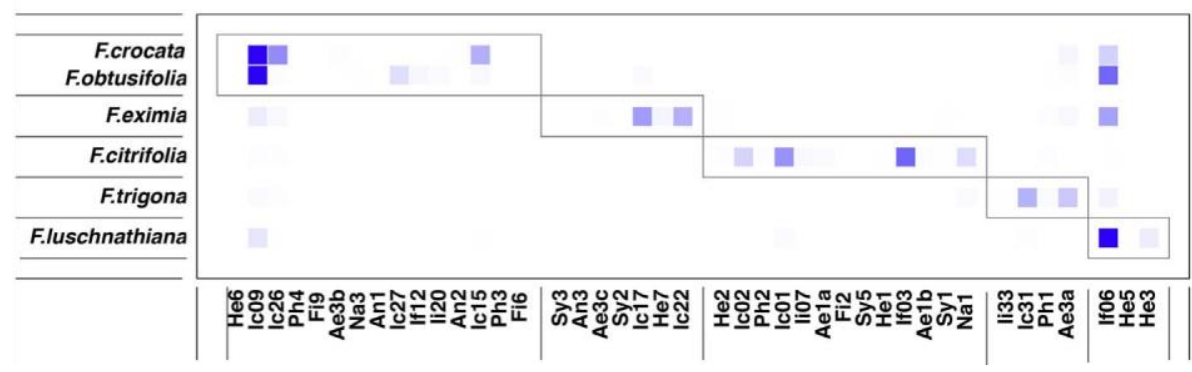



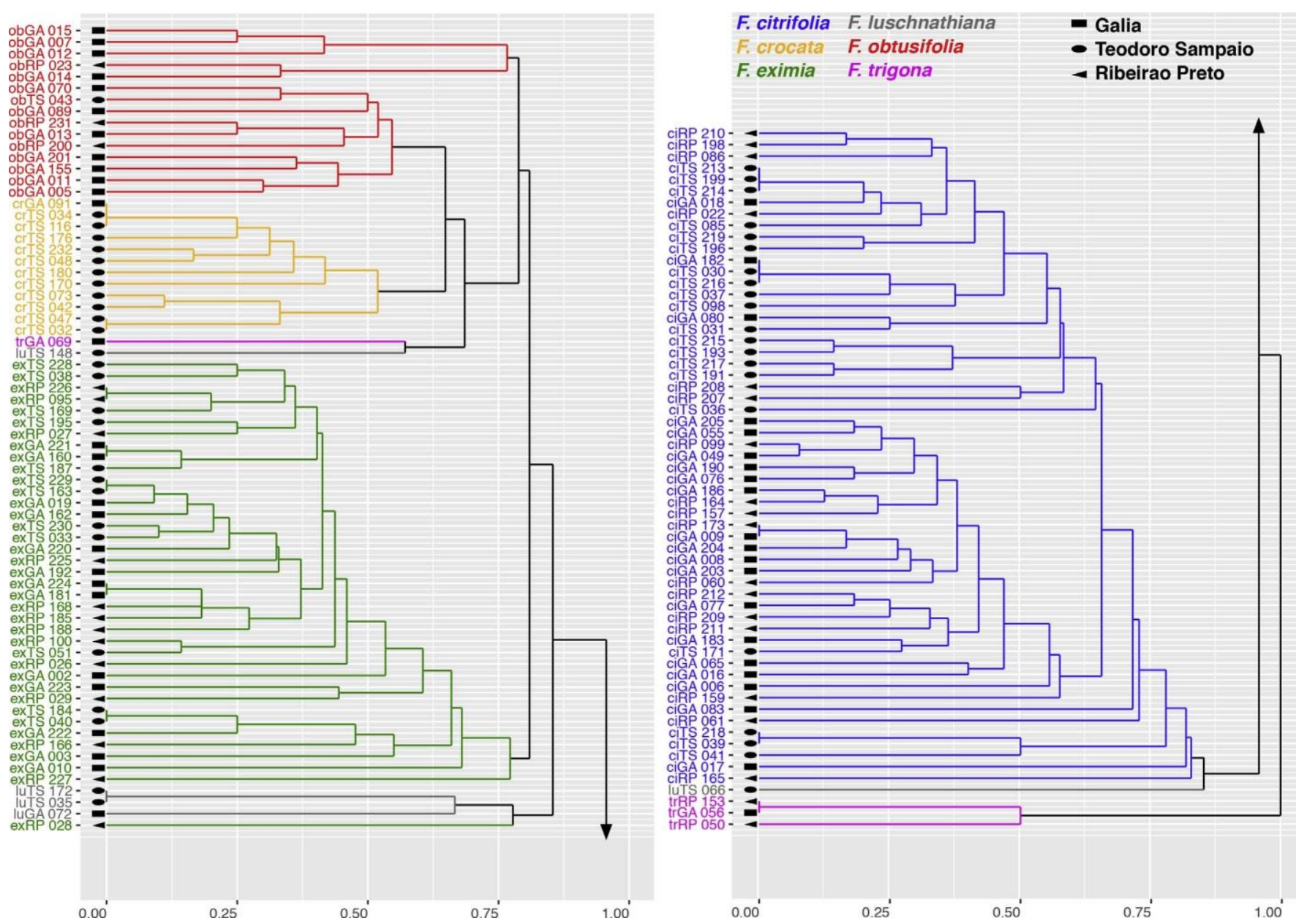

Fig. 4. Cluster analysis (UPGMA) for Jaccard similarity index of NPFW species present in each crop. Labels include host species $(\mathrm{ci}=\mathrm{F}$. citrifolia, $\mathrm{cr}=\mathrm{F}$. crocata $\mathrm{ex}=\mathrm{F}$. eximia, $\mathrm{lu}=\mathrm{F}$. luschnathiana, $o b=F$. obtusifolia and $\operatorname{tr}=F$. trigona) and sampling subset $(\mathrm{GA}=\mathrm{Gália}, \mathrm{RP}=$ Ribeirão Preto and TS = Teodoro Sampaio

Table 2 PERMANOVA analysis on the Jaccard distance from the presence/absence matrix of NPFW species in each sample (crop).

\begin{tabular}{lclll}
\hline & Df & F Model & R2 & Pr \\
\hline All hosts & & & & $\mathrm{P}=$ \\
Host & 5 & 28.45 & 0.50 & 0.0001 \\
Area & 2 & 5.63 & 0.04 & $\begin{array}{l}\mathrm{P}= \\
0.0001\end{array}$ \\
Host:Area & 7 & 1.81 & 0.05 & $\begin{array}{l}\mathrm{P}= \\
0.0007\end{array}$ \\
Residuals & 116 & & 0.41 & \\
F. eximia and ifolia & & & $\mathrm{P}=$ \\
F. citr $\quad 1$ & 81.12 & 0.43 & 0.0001
\end{tabular}


Host

$\begin{array}{lcccl}\text { Area } & 2 & 6.20 & 0.07 & \begin{array}{l}\mathrm{P}= \\ 0.0001\end{array} \\ \text { Host:Area } & 2 & 2.72 & 0.03 & \begin{array}{l}\mathrm{P}= \\ 0.0105\end{array} \\ \text { Residuals } & 89 & & 0.47 & \end{array}$

This interpretation is supported by total lack of the highly specific early gallers in $\mathrm{F}$. luschnathiana while all other figs hosted at least one species. Ficus trigona presents a somewhat more balanced community, with two abundant NPFW species (one of which was a specialist) and the presence of an early galler. Nevertheless, the proportion of NPFW comparatively to pollinators was very low suggesting that limited colonization by non-specialist NPFW resulted in reduced overall parasitism. Ficus obtusifolia presented a diversified community of NPFW with two early galler species. However, the community was dominated by two generalist species representing $87 \%$ of all NPFW. Ficus eximia and F. crocata presented more balanced communities with three abundant species ( $>10 \%$ of the NPFW) out of which only one was a generalist (Fig. 3A). Ficus eximia and F. crocata were the largest and tallest trees that we sampled (Berg and Villavicencio, 2004). They usually reach large sizes, consequently producing large crops. We may suggest that large size compensated for low density in allowing the survival of a diversified community of

Network indices, standard scores, and p-values calculated for the complete network and for the gall-maker and parasites (cleptoparasite + parasitoid) subsets. Aepocerus species were excluded from the analysis of gall-maker and parasitic subsets since information on their natural history is inconclusive (see topic 2.2).

Table 3

\begin{tabular}{|c|c|c|c|c|c|c|c|c|c|}
\hline & \multicolumn{3}{|c|}{ Whole Network } & \multicolumn{3}{|l|}{ Gall- } & \multicolumn{3}{|c|}{ Parasites } \\
\hline Indices & value & $\mathrm{Z}$ & p-value & value & $\mathrm{Z}$ & p-value & value & $\mathrm{z}$ & $\begin{array}{l}\mathrm{p}- \\
\text { value }\end{array}$ \\
\hline Connectance & 0.33 & -34.71 & $<0.001$ & 0.26 & -15.58 & $<0.001$ & 0.37 & -31.68 & $\begin{array}{l}< \\
0.001\end{array}$ \\
\hline $\mathrm{H}_{2}^{\prime}$ & 0.65 & 5.36 & $<0.001$ & 0.89 & 2.60 & $<0.001$ & 0.74 & 6.87 & $\begin{array}{l}< \\
0.001\end{array}$ \\
\hline $\begin{array}{l}\text { Modularity } \\
\text { (Q) }\end{array}$ & 0.53 & 89.74 & $<0.01$ & 0.34 & 123.41 & $<0.01$ & 0.53 & 254.06 & $\begin{array}{l}< \\
0.01\end{array}$ \\
\hline wNODF & 22.70 & -13.11 & $<0.001$ & 17.30 & -14.32 & $<0.001$ & 25.80 & -9.81 & $\begin{array}{l}< \\
0.001\end{array}$ \\
\hline
\end{tabular}




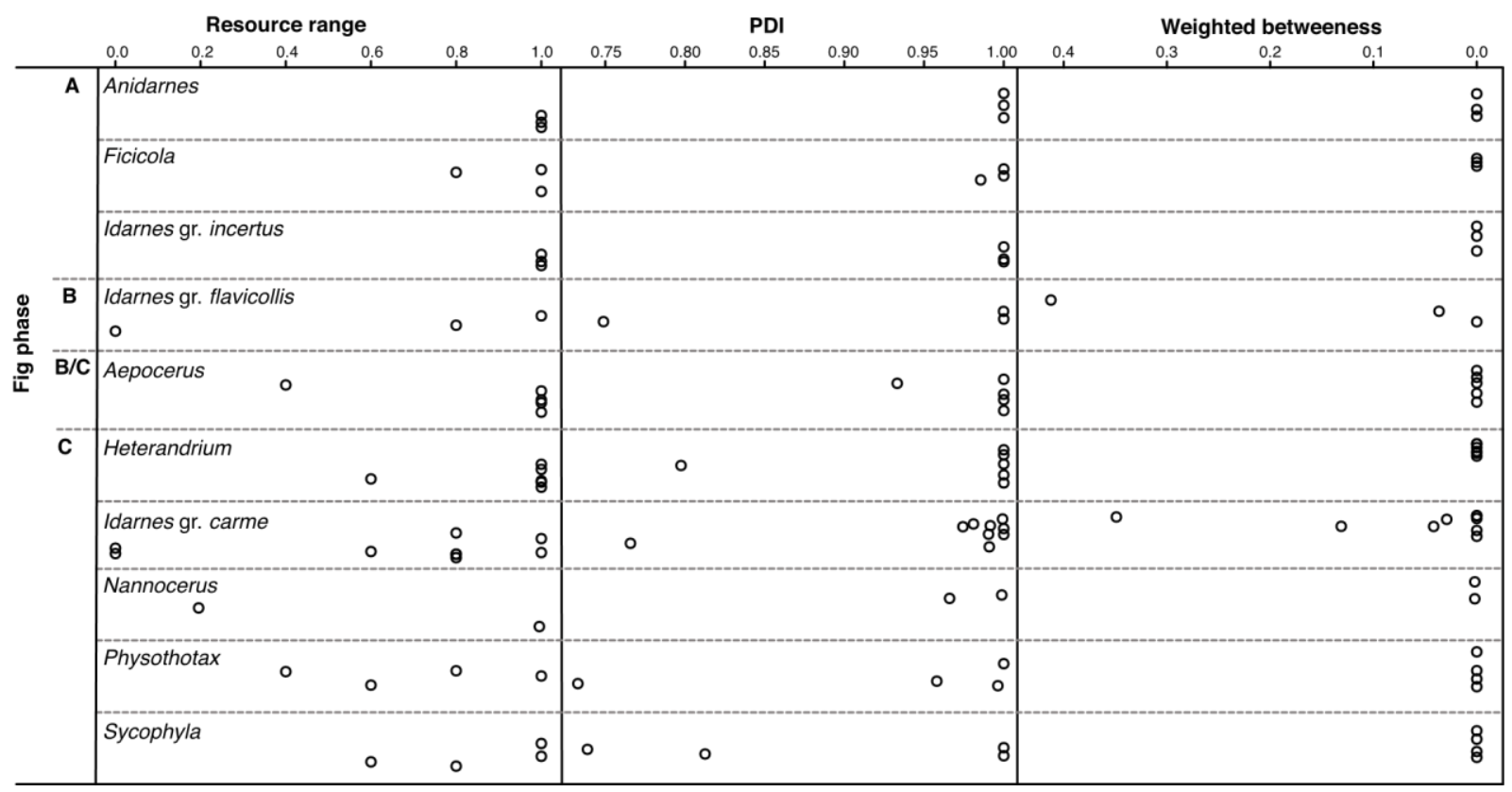

Fig. 5. Species-level indices calculated for NPFW species, sorted by genera and colonization phase. $\mathrm{A}=$ Early gall inducers; $\mathrm{B}=$ receptive phase colonizers; $\mathrm{B}-\mathrm{C}$ receptive or interfloral phase colonizer; and $\mathrm{C}=$ interfloral phase colonizers.

Table 4 Paired difference index comparison with null models. Ae $=$ Aepocerus; $\mathrm{He}=$ Heterandrium; Ic = Idarnes group carme; If = Idarnes group flavicollis; $\mathrm{Na}=$ Nannocerus; $\mathrm{Ph}$ $=$ Physothorax; Sy = Sycophila.

\begin{tabular}{llll}
\hline Species & PDI & z-score & $\begin{array}{l}\text { P- } \\
\text { value }\end{array}$ \\
\hline Ae3a & 0.93 & 8.80 & $<$ \\
He2 & 0.8 & 3.45 & 0.001 \\
& & $<$ \\
Ic09 & 0.77 & 26.4 & 0.001 \\
& & & $<$ \\
Ic26 & 0.97 & 20.41 & $<.001$ \\
& & & 0.001 \\
If06 & 0.75 & 21.36 & $<$ \\
& & & 0.001 \\
Ph1 & 0.73 & 4.09 & $<$ \\
& & & 0.001 \\
Sy1 & 0.74 & 1.80 & $<$ \\
& & & 0.003 \\
Sy3 & 0.81 & 0.32 & $=0.3$ \\
Na1 & 0.97 & 15.62 & $<$ \\
& & & 0.001 \\
\hline
\end{tabular}


NPFW. Indeed, while there is no published general overview of the diversity of NPFW communities, gynodioecious figs, which are often small in size, present simpler communities than the larger monoecious species. Hence we may suggest as a working hypothesis that aspects of a Ficus species density and size may play a role in determining the structure and specificity of their NPFW community. We may wonder how much local conditions - notably variation in local density of the different Ficus species - affect the composition of NPFW communities and patterns of host sharing.

This study presents data from three different locations spanning $500 \mathrm{~km}$, a quite large distance, but quite limited at the scale of Brazil. The local context is one of extreme recent habitat loss through deforestation (Coelho et al., 2014). We may therefore wonder whether the composition of NPFW communities and especially the presence of generalist wasp species is a product of recent events or whether it has to be explained by processes occurring over larger time scales. At the end of the 19th century Fritz Müller collected fig wasps on what he thought was a set of six distinct Ficus species belonging to section Americanae in Blumenau (Santa Catarina state, south of São Paulo state). According to Müller, Idarnes flavicollis was collected from five of these host species (Müller and Möller, 1915 p. 1073). We therefore conclude that I. flavicollis was already using several hosts over 100 years ago, before major deforestation. Hence the particularity of the NPFW communities associated with Ficus section Americanae in São Paulo state predates major human perturbation. Our collections from Amazonian Brazil and Costa Rica suggest higher NPFW specialization (Farache, Cruaud \& Rasplus, unpublished data). Therefore, the situation in Southern extra-Amazonian Brazil could be unusual and may be explained by 1) recent population expansions due to Pleistocene climatic oscillations $(<2.6$ Ma; Cohen et al., 2013; Francoso et al., 2016); 2) particular conditions associated with the region such as a globally relatively dry climate and the effect of oscillations of the regional climate or 3) the recent diversification of section Americanae (Cruaud et al., 2012). The fauna of NPFW associated with section Americanae is unique due to the overwhelming predominance of the subfamily Sycophaginae (59\%-99\% of NPFW in a host belonging to genus Idarnes). This is probably best explained by the recent diversification of this section. The presence of an Idarnes species in Dominican amber indicates that the Sycophaginae are associated with Ficus section Americanae for at least 15-20 Ma (Farache et al., 2016).

In terms of species richness, we observed a high number of parasitic species (cleptoparasites and parasitoids) compared to gall inducers (prefloral and receptive-phase colonizers). In terms of wasp abundance, interfloral colonizers were numerous, but receptive-phase colonizers were also highly frequent and sometimes outnumbered other species groups in the community. Prefloral colonizers were always observed in low abundance. They probably have their oviposition capacity constrained by flower development, as pistillate flowers are not completely developed at this phase (Basso-Alves et al., 2014). Therefore, they may use mechanisms of gall induction that differ from the one shown by receptive-phase colonizers. Wasps colonizing Ficus 
section Americanae at prefloral phase have relatively thicker and shorter ovipositors. They induce large galls that may occupy a considerable volume of the fig lumen, diminishing the space for the development of seeds and of other wasps. The induction of large galls is usually correlated to small brood sizes (Bronstein, 1999). Receptive-phase colonizers arrive concomitantly with pollinators, and compete with them for oviposition sites (Cook et al., 1997; Elias et al., 2012). Species that oviposit during the receptive phase might use chemical cues similar to those attracting pollinators to their host fig species, as experimentally demonstrated for F. racemosa (Proffit et al., 2007). Since the fig receptive phase only lasts for a few days, and oviposition and gall-inducing mechanisms in receptive flowers are complex (Elias et al., 2012), this feeding habit may be constraining and restricted to a few groups. Idarnes flavicollis is to our knowledge the first documented case of a galler at receptivity developing in large numbers in several host figs. The emission of species-specific volatile compounds peaks at fig receptivity, allowing recognition of the host fig by their specific pollinators. As I. flavicollis develops in large numbers in several host figs, we may propose that the differences among species in receptive fig odours is a trait that allows pollinating wasp to locate their specific host, but it is in no way a constraint that would prevent a wasp from using several hosts. Some volatile compounds in the fig scent blend are common among different fig species (Hossaert-McKey et al., 2016) and Idarnes flavicollis might use them to identify its hosts. Interfloral phase is relatively much longer than the receptive phase (about 30-40 days), thus the temporal window to locate trees is probably less constraining for species colonizing figs during the interfloral phase. We suggest that this larger time frame for oviposition may open opportunities for diversification of species and of feeding regime. Indeed, interfloral colonizers can be cleptoparasites or parasitoids (Cook and Rasplus, 2003; Kjellberg et al., 2005), yet some interfloral colonizers show high plasticity in their feeding regime and a few species can even use seeds as a larval resource (Pereira et al., 2007; Wang et al., 2014).

Most early gall-maker species observed in this study were host specific, a feature consistent with observations in systematic studies of gall-inducing Neotropical NPFW clades (Farache et al., 2013, 2017). For the other groups, variation in specificity was high, and species ranged from strictly specific to generalist, without a clear taxonomic pattern. Probably a multitude of factors may influence the host range in NPFW. For instance, network analyses suggested that both gallmaker and parasitic subsets are specialized. Further taxonomic and evolutionary studies within each lineage are needed in order to understand host specialization patterns in fig wasps.

Although fig wasp species using more than one host were frequent, 55\% of the NPFW species occurred in only one Ficus species. Overall, host-plant specificity tends to be higher in concealed herbivorous guilds than in externally feeding insects. Some studies reported 50\% or more specialist species in leaf-chewing, sap-sucking or seed-eating insect communities (Diniz and Morais, 1997; Novotny and Basset, 2005; Odegaard, 2000; Thomas, 1990), and therefore host specialization may rise in antagonistic relationships. Indeed, gall-inducing insects - as endophytic organisms - seem to be highly host-specific, yet sampling difficulties and lack of 
quantitative data hinder the understanding of their community structure (Bourg and Hanson, 2014; Carneiro et al., 2009).

Non-pollinating fig wasp species occurring in more than one host species were observed in previous studies, yet analyses on the whole community of NPFW are lacking for most biogeographic regions. Our observations on the Neotropical fauna associated with Ficus section Americanae are congruent with previous molecular studies in the same Ficus section (Marussich and Machado, 2007), in which 23\% of the species occurred in more than one host. In the Afrotropical region, species occurring in several hosts were observed in interfloral colonizers (McLeish et al., 2010). Studies in a NPFW genus (Philotrypesis) in Asia show that they may be mostly host specific, with the exception of two species that are associated with the hosts F. microcarpa and F. benjamina (Zhou et al., 2012). Sycophaga is distributed through the Old World and most species seem to be host specific (Weiblen and Bush, 2002) but an internal receptive phase colonizer, Sycophaga silvestrii, seem to occur in two hosts in Africa (Kerdelhué et al., 2000). For both Philotrypesis and Sycophaga, the documented cases of occurrence in multiple hosts probably indicate marginal use of an alternative host by a specialist wasp. Thus, the NPFW seem to be less specific in the Neotropical region than in the Afrotropical region, and most specific in the remaining tropical Old World communities. Comparisons between biogeographic regions are still limited by (1) the lack of quantitative data and (2) the lack of sampling of the whole community.

The NPFW-Ficus network was highly un-nested, and instead significantly modular. This structure may be expected for specific antagonistic relationships such as endophytic insects host plants and host parasitoid interactions. Such structure indicates that the community subset associated with each host species poorly interact with other groups, indicating specialization (Dormann and Strauss, 2014). Although some species (interfloral colonizers especially) showed a wide host range, they tended to show asymmetric ovule occupancy rates in different hosts, which indicate preference or differential development success according to host. Moreover, cluster analyses showed that samples from the same host fig were more similar to each other irrespective to their geographic locations. This pattern indicates that although NPFW species are shared among hosts, the faunal composition is idiosyncratic for each host, suggesting specificity. Studies on host choices by insects show that multiple factors govern the evolution of host specificity. Allelochemicals, feeding habits, nutritional chemistry and plant morphology are major determinants of host preference and specificity (Thompson and Pellmyr, 1991). According to the current knowledge, host preference in NPFW seems to reflect the selection imposed by the broad morphological and physiological diversity of fig trees. Ficus species vary greatly in fig size, fig wall thickness, number and size of pistillate flowers, and chemical scent cues (Proffit et al., 2007). Due to the constraints imposed by these plant traits, NPFWs may oviposit preferentially in a fig tree to which they are better adapted. Indeed, NPFW species exhibit variable ovipositor lengths and structures, which correlate both with trophic ecology and phenotypic characteristics of the figs, such as wall thickness (Elias et al., 2017; Farache et 
al., 2016; Ghara et al., 2011; Zhen et al., 2005). Thus, such morphological variation may be related to host specialization.

Ecological specialization theory suggests that specialists should outperform generalist species due to the presence of specific adaptations that allow them to exploit a particular host. Generalist species are adapted to develop in a suite of hosts, but may not present a combination of characteristics that allow them to exploit all species they use efficiently - "the jack of all trades is a master of none" (Forister et al., 2012; Futuyma and Moreno, 1988). However, this does not appear to be the case for the gall-maker Idarnes flavicollis and the cleptoparasite Idarnes sp. 9. Both species occurred in all fig species available, and were the most abundant species in some of their host plants. Therefore, we observed that, at least in this Neotropical NPFW communities, more generalized species may have a higher ovule occupancy rate in some hosts than strict specialists. This observation may be related to the scarcity of the resources fig wasps utilize. The low abundances of fig trees in extra-Amazonian Neotropical forests (Coelho et al., 2014) coupled with the asynchrony of fig fructification result in both spatial and temporal constrains for NPFW to find their hosts at the right stage of development. In this context, generalist species may easily find suitable figs to lay eggs, which may explain the high abundances of I. flavicollis and I. sp. 9.

\section{Conclusion}

Specialization in natural communities and guilds has rarely been quantified due to the difficulty to generate informative networks and to obtain representative samples of whole communities (Ballantyne et al., 2015; Forister et al., 2012). The NPFW associated with Ficus show diverse life history traits and represent a suitable and informative model to quantify specialization since it is possible to obtain a quantitative measure of the relative ovule occupancy rate of each species in the whole community. We observed that despite the occurrence of wasps that are not restricted to a single host species, the community of NPFW associated with Ficus section Americanae shows a specialized structure. This study opens a new perspective in our understanding of fig wasp communities. Further analyses in other biogeographic regions will allow a better understanding of the evolution of host specificity in symbiotic insect-plant relationships.

Morphological identification of fig wasps at species level can be challenging (especially for pollinators), and the lack of a taxonomic background may hinder the understanding of fig wasp communities.

Nevertheless, while sampling a local community, morphological identification can be achieved, and the sampling of cryptic species may be relatively unlikely. Indeed, Darwell and Cook (2017) have shown that, in Australia, cryptic NPFW species are largely allopatric. Our molecular analyses in Idarnes discussed in supplementary material show that when the same morphospecies was found on multiple hosts, it represented the same biological species. Yet a thorough molecular sampling would be necessary to identify cryptic species, especially if they 
are rare. Further, care should be taken to avoid considering coding NUMTS or heteroplasms as cryptic species (Cruaud et al., 2017).

In this paper we described how Neotropical NPFW communities are structured and their intricate patterns of specialization and generalism. We suggest that these patterns may vary over continents, and even within the neotropics. Therefore, we encourage further quantitative sampling in other biomes and biogeographic regions in order to test this conjecture.

\section{Funding}

This work was supported by São Paulo Research Foundation (FAPESP) grants: 2004/102994, 2007/06054-4, 2008/03272-3, 2008/ 52378-9, 2011/21485-7, 2015/06430-2 and 2015/25417-7. R.A.S.P. was funded by CNPq (grant 306078/2014-7).

\section{Acknowledgments}

We wish to thank L.P. Rocha, L.F.M. Coelho, M.D. Medeiros, A.C. Cazarotti and P. R. Furini for contributing to field sampling. We also thank Gwenaëlle Genson (CBGP) for collaboration with molecular analyses in Idarnes. We are grateful to the editor Steve Compton and two anonymous reviewers for comments that improved the manuscript.

Supplementary data related to this article can be found at http://dx.doi.org/10.1016/j.actao.2018.02.006.

\section{References}

Anderson, M.J., 2001. A new method for non-parametric multivariate analysis of variance. Austral Ecol. 26, 32-46.

Ballantyne, G., Baldock, K.C.R., Willmer, P.G., 2015. Constructing more informative plantpollinator networks: visitation and pollen deposition networks in a heathland plant community. P Roy Soc. B-Biol. Sci. 282, 14-22.

Barrat, A., Barthelemy, M., Pastor-Satorras, R., Vespignani, A., 2004. The architecture of complex weighted networks. P Natl. Acad Sci. USA 101, 3747-3752.

Bascompte, J., Jordano, P., 2006. The structure of plant-animal mutualistic networks. In: Pascual, M., Dunne, J. (Eds.), Ecological Networks. Oxford University Press, Oxford, pp. 143-159.

Bascompte, J., Jordano, P., Melián, C.J., Olesen, J.M., 2003. The nested assembly of plant-animal mutualistic networks. P Natl. Acad Sci. USA 100, 9383-9387.

Bascompte, J., Jordano, P., Olesen, J.M., 2006. Asymmetric coevolutionary networks facilitate biodiversity maintenance. Science 312, 431-433.

Basso-Alves, J.P., Pereira, R.A.S., Peng, Y.Q., Teixeira, S.P., 2014. Different ontogenetic processes promote dicliny in Ficus L. (Moraceae). Acta Oecol. 57, 5-16.

Beardsley, J.W., Rasplus, J.-Y., 2001. A new species of Josephiella (Hymenoptera: Agaonidae) forming leaf galls on Ficus microcarpa L. (Moraceae). J. Nat. Hist. 35, 33-40. 
Berg, C.C., Villavicencio, X., 2004. Taxonomic studies on Ficus (Moraceae) in the West Indies, extra-amazonian Brazil, and Bolivia. Ilicifolia 5, 1-132.

Blüthgen, N., Menzel, F., Hovestadt, T., Fiala, B., Blüthgen, N., 2007. Specialization, constraints, and conflicting interests in mutualistic networks. Curr. Biol.: CB 17, 341-346.

Bouček, Z., 1993. The genera of chalcidoid wasps from Ficus fruit in the New World. J. Nat. Hist. 27, 173-217.

Bourg, A., Hanson, P.E., 2014. Chapter 10 Host specificity of gall midges (Diptera: Cecidomyiidae) on ten species of Inga (Fabaceae). In: Fernandes, G.W., Santos, J.C. (Eds.), Neotropical Insect Galls. Springer, Netherlands, pp. 427.

Brandes, U., Kenis, P., Wagner, D., 2003. Communicating centrality in policy network drawings. Ieee T Vis Comput. Gr. 9, 241-253.

Bronstein, J.L., 1999. Natural history of Anidarnes bicolor (Hymenoptera: Agaonidae), a galler of the Florida strangling fig (Ficus aurea). Fla. Entomol. 82, 454-461.

Burt, R.S., 1976. Positions in Networks. Soc. Forces 55, 93-122.

Butts, C.T., 2014. Sna: Tools for Social Network Analysis. $\quad$ R package version 2.3-2.

Carneiro, M.A.A., Branco, C.S.A., Braga, C.E.D., Almada, E.D., Costa, M.B.M., Maia, V.C., Fernandes, G.W., 2009. Are gall midge species (Diptera, Cecidomyiidae) host-plant specialists? Rev. Bras. Entomol. 53, 365-378.

Coelho, L.F.M., Ribeiro, M.C., Pereira, R.A.S., 2014. Water availability determines the richness and density of fig trees within Brazilian semideciduous forest landscapes.

Acta Oecol. 57, 109-116.

Cohen, K.M., Finney, S., Gibbard, P.L., Fan, J.-X., 2013. International Chronostratigraphic Chart v. 2015-01.

Compton, S.G., Hawkins, B.A., 1992. Determinants of species richness in southern African fig wasp assemblages. Oecologia 91, 68-74.

Compton, S.G., van Noort, S., 1992. Southern african fig wasps (Hymenoptera, Chalcidoidea) resource utilization and host relationships. Proc. K. Ned. Akad. Wet. Biol. Chem. Geol. Phys. Med. Sci. 95, 423-435.

Conchou, L., Ciminera, M., Hossaert-McKey, M., Kjellberg, F., 2014. The non-pollinating fig wasps associated with Ficus guianensis: community structure and impact of the large species on the fig/pollinator mutualism. Acta Oecol. 57, 28-37.

Cook, J.M., Compton, S.G., Herre, E.A., West, S.A., 1997. Alternative mating tactics and extreme male dimorphism in fig wasps. Proc. R. Soc. Lond. Ser. B Biol. Sci. 264, 747-754. Cook, J.M., Rasplus, J.-Y., 2003. Mutualists with attitude: coevolving fig wasps and figs. Trends Ecol. Evol. 18, 241-248.

Cook, J.M., Segar, S.T., 2010. Speciation in fig wasps. Ecol. Entomol. 35, 54-66.

Cornille, A., Underhill, J.G., Cruaud, A., Hossaert-McKey, M., Johnson, S.D., Tolley, K.A., Kjellberg, F., van Noort, S., Proffit, M., 2012. Floral volatiles, pollinator sharing and diversification in the fig-wasp mutualism: insights from Ficus natalensis, and its two wasp pollinators (South Africa). P Roy Soc. B-Biol. Sci. 279, 1731-1739.

Cruaud, A., Jabbour-Zahab, R., Genson, G., Couloux, A., Peng, Y.-Q., Rong, Y.D., 
Ubaidillah, R., Pereira, R.A.S., Kjellberg, F., van Noort, S., Kerdelhue, C., Rasplus, J.Y., 2011a. Out of Australia and back again: the world-wide historical biogeography of nonpollinating fig wasps (Hymenoptera: Sycophaginae). J. Biogeogr. 38, 209-225.

Cruaud, A., Jabbour-Zahab, R., Genson, G., Kjellberg, F., Kobmoo, N., van Noort, S., DaRong, Y., Yan-Qiong, P., Ubaidillah, R., Hanson, P.E., Santos-Mattos, O., Farache, F.H.A., Pereira, R.A.S., Kerdelhue, C., Rasplus, J.-Y., 2011b. Phylogeny and evolution of life-history strategies in the Sycophaginae non-pollinating fig wasps (Hymenoptera, Chalcidoidea). BMC Evol. Biol. $11,15$.

Cruaud, A., Rønsted, N., Chantarasuwan, B., Chou, L.-S., Clement, W.L., Couloux, A., Cousins, B., Genson, G., Harrison, R.D., Hanson, P.E., Hossaert-McKey, M., JabbourZahab, R., Jousselin, E., Kerdelhué, C., Kjellberg, F., Lopez-Vaamonde, C., Peebles, J., Peng, Y.-Q., Pereira, R.A.S., Schramm, T., Ubaidillah, R., van Noort, S., Weiblen, G.D., Yang, D.-R., Yodpinyanee, A., Libeskind-Hadas, R., Cook, J.M., Rasplus, J.-Y., Savolainen, V., 2012. An extreme case of plant-insect co-diversification: figs and figpollinating wasps. Syst. Biol. 61, 1029-1047.

Cruaud, P., Rasplus, J.Y., Rodriguez, L.J., Cruaud, A., 2017. High-throughput sequencing of multiple amplicons for barcoding and integrative taxonomy. Sci. Rep. 7, 41948.

Darwell, C.T., Cook, J.M., 2017. Cryptic diversity in a fig wasp community - morphologically differentiated species are sympatric but cryptic species are allopatric. Mol. Ecol. 26, 5358. de Vries, A., Ripley, B.D., 2016. Ggdendro: Create Dendrograms and Tree Diagrams Using 'ggplot2'. R package version 0.1-20.

Diniz, I.R., Morais, H.C., 1997. Lepidopteran caterpillar fauna of cerrado host plants.

Biodivers. Conserv. 6, 817-836.

Dormann, C.F., 2011. How to be a specialist? Quantifying specialisation in pollination networks. Network Biol. 1, 1-20.

Dormann, C.F., Fründ, J., Blüthgen, N., Gruber, B., 2009. Indices, graphs and null models: analyzing bipartite ecological networks. Open Ecol. J. 2, 7-24.

Dormann, C.F., Gruber, B., Fründ, J., 2008. Introducing the bipartite package: analysing ecological networks. R. News 8, 8-11.

Dormann, C.F., Strauss, R., 2014. A method for detecting modules in quantitative bipartite networks. Methods Ecol .Evol. 5, 90-98.

Dorogovtsev, S.N., Mendes, J.F.F., 2003. Evolution of Networks: from Biological Nets to the Internet and WWW. Oxford University Press.

Dunne, J.A., Williams, R.J., Martinez, N.D., 2002. Food-web structure and network theory: the role of connectance and size. P Natl. Acad Sci. USA 99, 12917-12922.

Elias, L.G., do Ó, V.T., Farache, F.H.A., Pereira, R.A.S., 2007. Effect of non-pollinating fig wasps over fig-fig wasp mutualism. Iheringia Ser. Zool. 97, 253-256.

Elias, L.G., Kjellberg, F., Farache, F.H.A., Almeida, E.A.B., Rasplus, J.Y., Cruaud, A., Peng, Y.Q., Yang, D.R., Pereira, R.A.S., 2017. Ovipositor morphology correlates with life history evolution in agaonid fig wasps. Acta. Oecol. vol. 1-8.

Elias, L.G., Menezes Jr., A.O., Pereira, R.A.S., 2008. Colonization sequence of non-pollinating fig wasps associated with Ficus citrifolia in Brazil. Symbiosis 45, 107-111. 
Elias, L.G., Teixeira, S.P., Kjellberg, F., Pereira, R.A.S., 2012. Diversification in the use of resources by Idarnes species: bypassing functional constraints in the fig-fig wasp interaction. Biol. J. Linn. Soc. 106, 114-122.

Farache, F.H.A., Cruaud, A., Genson, G., Pereira, R.A.S., Rasplus, J.-Y., 2013. Taxonomic revision and molecular phylogeny of the fig wasp genus Anidarnes Bouček, 1993 (Hymenoptera, Sycophaginae). Syst. Entomol. 38, 14-34.

Farache, F.H.A., Cruaud, A., Genson, G., Rasplus, J.Y., Pereira, R.A.S., 2017. Taxonomic revision and molecular phylogenetics of the Idarnes incertus species-group (Hymenoptera, Agaonidae, Sycophaginae). PeerJ 5, e2842.

Farache, F.H.A., Rasplus, J.-Y., Azar, D., Pereira, R.A.S., Compton, S.G., 2016. First record of a non-pollinating fig wasp (Hymenoptera: Sycophaginae) from Dominican amber, with estimation of the size of its host figs. J. Nat. Hist. 50, 2237-2247.

Forister, M.L., Dyer, L.A., Singer, M.S., Stireman, J.O., Lill, J.T., 2012. Revisiting the evolution of ecological specialization, with emphasis on insect-plant interactions. Ecology 93, 981-991.

Forister, M.L., Feldman, C., 2011. Phylogenetic cascades and the origins of tropical diversity. Biotropica 1-9.

Francoso, E., Zuntini, A.R., Carnaval, A.C., Arias, M.C., 2016. Comparative phylogeography in the Atlantic forest and Brazilian savannas: pleistocene fluctuations and dispersal shape spatial patterns in two bumblebees. BMC Evol. Biol. 16.

Friedkin, N.E., Johnsen, E.C., 1997. Social positions in influence networks. Soc. Net. 19, 209222.

Futuyma, D.J., Moreno, G., 1988. The evolution of ecological specialization. Annu. Rev. Ecol. Syst. 19, 207-233.

Galeano, J., Pastor, J.M., Iriondo, J.M., 2009. Weighted-Interaction Nestedness Estimator (WINE): a new estimator to calculate over frequency matrices. Environ. Modell.

Softw. 24, 1342-1346.

Galil, J., Eisikowitch, D., 1969. Further studies on the pollination ecology of Ficus sycomorus L. (Hymenoptera, Chalcidoidea, Agaonidae). Tijd Entomol. 112, 1-13.

Ghara, M., Kundanati, L., Borges, R.M., 2011. Nature's swiss army knives: ovipositor structure mirrors ecology in a multitrophic fig wasp community. PLoS One 6, e23642 23641-23649.

Ghara, M., Ranganathan, Y., Krishnan, A., Gowda, V., Borges, R.M., 2014. Divvying up an incubator: how parasitic and mutualistic fig wasps use space within their nursery microcosm. Arthropod. Plant Interact. 8, 191-203.

Hossaert-McKey, M., Proffit, M., Soler, C.C.L., Chen, C., Bessiere, J.M., Schatz, B., Borges, R.M., 2016. How to be a dioecious fig: chemical mimicry between sexes matters only when both sexes flower synchronously. Sci. Rep. 6, 21236.

Jansen-Gonzalez, S., Teixeira, S.D., Kjellberg, F., Pereira, R.A.S., 2014. Same but different: larval development and gall-inducing process of a non-pollinating fig wasp compared to that of pollinating fig-wasps. Acta Oecol. 57, 44-50. 
Jiang, Z.-F., Huang, D.-W., Chen, L.-L., Zhen, W.-Q., Fu, Y.-G., Peng, Z.Q., 2006. Rampant host switching and multiple female body colour transitions in Philotrypesis (Hymenoptera: Chalcidoidea: Agaonidae). J. Evol. Biol. 19, 1157-1166.

Jordano, P., 1987. Patterns of mutualistic interactions in pollination and seed dispersal connectance, dependence asymmetries, and coevolution. Am. Nat. 129, 657-677.

Joseph, K.J., 1958. Recherches sur les Chalcidiens, Blastophaga psenes (L.) et Philotrypesis caricae (L.), du figuier (Ficus carica L.). Annales des Sci. NaturelL.Paris (Zoologie) 20, 197260.

Jousselin, E., van Noort, S., Rasplus, J.-Y., Greeff, J.M., 2006. Patterns of diversification of Afrotropical otiteselline fig wasps: phylogenetic study reveals a double radiation across host figs and conservatism of host association. J. Evol. Biol. 19, 253-266.

Kerdelhué, C., Rossi, J.-P., Rasplus, J.-Y., 2000. Comparative community ecology studies on old world figs and fig wasps. Ecology 81, 2832-2849.

Kjellberg, F., Jousselin, E., Hossaert-McKey, M., Rasplus, J.-Y., 2005. Biology, ecology, and evolution of fig-pollinating wasps (Chalcidoidea, Agaonidae). In: In: Raman, A., Schaefer, C.W., Withers, T.M. (Eds.), Biology, Ecology and Evolution of Gall-inducing Arthropods, vol. 2. Science Publishers, Inc., New Hampshire, pp. 539-572.

Legendre, P., Legendre, L., 1998. Numerical Ecology, second ed. Elsevier, Amsterdam.

Ma'ayan, A., 2011. Introduction to Network analysis in systems biology. Sci. Signal. 4 tr5. Machado, A.F.P., Rønsted, N., Bruun-Lund, S., Pereira, R.A.S., Queiroz, L.P.d., 2018. Atlantic forest to the all Americas: biogeographical history and divergence times of Neotropical Ficus (Moraceae). Mol. Phylogenet. Evol. 122, 46-58.

Machado, C.A., Robbins, N., Gilbert, M.T.P., Herre, E.A., 2005. Critical review of host specificity and its coevolutionary implications in the fig/fig-wasp mutualism. P Natl.

Acad Sci. USA 102, 6558-6565.

Martín González, A.M., Dalsgaard, B., Olesen, J.M., 2010. Centrality measures and the importance of generalist species in pollination networks. Ecol. Complex. 7, 36-43.

Marussich, W.A., Machado, C.A., 2007. Host-specificity and coevolution among pollinating and nonpollinating New World fig wasps. Mol. Ecol. 16, 1925-1946.

McArdle, B.H., Anderson, M.J., 2001. Fitting multivariate models to community data: a comment on distance-based redundancy analysis. Ecology 82, 290.

McLeish, M.J., Beukman, G., van Noort, S., Wossler, T.C., 2012. Host-plant species conservatism and ecology of a parasitoid fig wasp genus (Chalcidoidea; Sycoryctinae; Arachonia). PLoS One 7, e44804.

McLeish, M.J., van Noort, S., Tolley, K.A., 2010. African parasitoid fig wasp diversification is a function of Ficus species ranges. Mol. Phylogenet. Evol. 57, 122-134.

Memmott, J., 1999. The structure of a plant-pollinator food web. Ecol. Lett. 2, 276-280.

Memmott, J., Waser, N.M., Price, M.V., 2004. Tolerance of pollination networks to species extinctions. P Roy Soc. B-Biol. Sci. 271, 2605-2611.

Müller, F., 1886. Zur Kenntnis der Feigenwespen. Entomol. Nachrich. 13, 193-199.

Müller, F., Möller, A., 1915. Fritz Müller, Werke, Briefe und Leben. Gesammelt und hrsg. von Dr. Alfred Möller. G. Fischer, Jean. 
Novotny, V., Basset, Y., 2005. Host specificity of insect herbivores in tropical forests. P Roy Soc. B-Biol. Sci. 272, 1083-1090.

Odegaard, F., 2000. The relative importance of trees versus lianas as hosts for phytophagous beetles (Coleoptera) in tropical forests. J. Biogeogr. 27, 283-296.

Oksanen, J., Blanchet, F.G., Friendly, M., Kindt, R., Legendre, P., McGlinn, D., Minchin,

P.R., O'Hara, R.B., Simpson, G.L., Solymos, P., Stevens, M.H.H., Szoecs, E., Wagner, H., 2017. vegan: Community Ecology Package. R package version 2.4-4.

Olesen, J.M., Bascompte, J., Dupont, Y.L., Jordano, P., 2007. The modularity of pollination networks. P Natl. Acad Sci. USA 104, 19891-19896.

Patefield, W.M., 1981. Algorithm AS 159: an efficient method of generating random R $\times \mathrm{C}$ tables with given row and column totals. J. Royal Statis. Soc. Series C (Applied Statistics) 30, 91-97.

Peng, Y.-Q., Yang, D.-R., Duang, Z.-B., 2005. The population dynamics of a non-pollinating fig wasp on Ficus auriculata at Xishuangbanna, China. J. Trop. Ecol. 21, 581-584.

Pereira, R.A.S., Teixeira, S.P., Kjellberg, F., 2007. An inquiline fig wasp using seeds as a resource for small male production: a potential first step for the evolution of new feeding habits? Biol. J. Linn. Soc. 92, 9-17.

Poisot, T., Canard, E., Mouquet, N., Hochberg, M.E., 2012. A comparative study of ecological specialization estimators. Methods Ecol. Evol. 3, 537-544.

Prado, P.I., Lewinsohn, T.M., 2004. Compartments in insect-plant associations and their consequences for community structure. J. Anim. Ecol. 73, 1168-1178.

Proffit, M., Schatz, B., Borges, R.M., Hossaert-Mckey, M., 2007. Chemical mediation and niche partitioning in non-pollinating fig-wasp communities. J. Anim. Ecol. 76, 296-303.

R Core Team, 2017. R: a Language and Environment for Statistical Computing. R Foundation for Statistical Computing, Vienna, Austria.

Rasplus, J.-Y., Kerdelhue, C., Le Clainche, I., Mondor, G., 1998. Molecular phylogeny of fig wasps. Agaonidae are not monophyletic. C. R. Acad. Sci. Ser. III Sci. Vie 321, 517-527.

Segar, S.T., Dunn, D.W., Darwell, C.T., Cook, J.M., 2013a. How to be a fig wasp down under: the diversity and structure of an Australian fig wasp community. Acta Oecol. 57, 17-27.

Segar, S.T., Pereira, R.A.S., Compton, S.G., Cook, J.M., 2013b. Convergent structure of multitrophic communities over three continents. Ecol. Lett. 16, 1436-1445.

Taudiere, A., Munoz, F., Lesne, A., Monnet, A.C., Bellanger, J.M., Selosse, M.A., Moreau, P.A., Richard, F., 2015. Beyond ectomycorrhizal bipartite networks: projected networks demonstrate contrasted patterns between early- and late-successional plants in Corsica. Front. Plant Sci. 6.

Thomas, C.D., 1990. Herbivore diets, herbivore colonization, and the escape hypothesis. Ecology 71, 610-615.

Thompson, J.N., Pellmyr, O., 1991. Evolution of oviposition behavior and host preference in Lepidoptera. Annu. Rev. Entomol. 36, 65-89.

Tzeng, H.-Y., Tseng, L.-J., Ou, C.-H., Lu, K.-C., Lu, F.-Y., Chou, L.-S., 2008. Confirmation of the parasitoid feeding habit in Sycoscapter, and their impact on pollinator abundance in Ficus formosana. Symbiosis 45, 129-134. 
Vázquez, D.P., Melián, C.J., Williams, N.M., Blüthgen, N., Krasnov, B.R., Poulin, R., 2007. Species abundance and asymmetric interaction strength in ecological networks. Oikos 116, 1120-1127.

Wang, R., Matthews, A., Ratcliffe, J., Barwell, L.J., Peng, Y.Q., Chou, L.S., Yu, H., Yang, H.W., Compton, S.G., 2014. First record of an apparently rare fig wasp feeding strategy: obligate seed predation. Ecol. Entomol. 39, 492-500.

Weiblen, G.D., Bush, G.L., 2002. Speciation in fig pollinators and parasites. Mol. Ecol. 11, 15731578.

Zhen, W.-Q., Huang, D.-W., Xiao, J.-H., Yang, D.-R., Zhu, C.-D., Xiao, H., 2005. Ovipositor length of three Apocrypta species: effect on oviposition behavior and correlation with syconial thickness. Phytoparasitica 33, 113-120.

Zhou, M.J., Xiao, J.H., Bian, S.N., Li, Y.W., Niu, L.M., Hu, H.Y., Wu, W.S., Murphy, R.W., Huang, D.W., 2012. Molecular approaches identify known species, reveal cryptic species and verify host specificity of Chinese Philotrypesis (Hymenoptera:

Pteromalidae). Mol. Ecol. Resour. 12, 598-606. 